\title{
Impact of financial constraints on the development of Vietnam's firms
}

\author{
Hung Nguyen Viet ${ }^{a^{*}}$, Hoa Ha Quynh ${ }^{a}$ and Thanh To Trung
}

${ }^{a}$ Faculty of Economics, National Economics University, Vietnam

${ }^{b}$ National Economics University, Vietnam

\section{CH R O N I C L E}

\section{Article history:}

Received: October 14, 2019

Received in revised format:

November 292019

Accepted: January 15, 2020

Available online:

January 15,2020

Keywords:

Financial constraints

Productivity growth

Dynamic Panel Data model

Ordered Probit and Logit Models

TFP and TFP growth

Vietnam

\section{A B S T R A C T}

This paper examines the impact of financial constraints on the development of Vietnamese firms driven by Total Factor Productivity (TFP) growth at the firm level. The effects of financial constraints by FCIf index on TFP growth of 97,860 firms are estimated by applying Dynamic Panel Data model over the period 2012-2017. The results show that there was a negative correlation between FCIf and labor productivity growth and TFP growth in all industries. While FCIf index is increased by 0.1 , TFP growth of firms is reduced by $3.71 \%$. The results also show that there was an inverse relationship between FCIf index, and the size of value added and assets of firms. Firms operating in manufacturing, wholesale and retail trade, and private firms face the biggest financial constraints.

(C) 2020 by the authors; licensee Growing Science, Canada

\section{Introduction}

The effect of financial constraints on the development of firms has been received much attention from academics and policymakers. Academic studies believe that financial constraints are important factors in making investment decisions of firms and these constrains are closely related to the ability to access external capital of firms. The financial status and the accessibility of external capital of the enterprise have significant effects on firm operation such as profitability and added value. Most studies show that firms, which are less financially constrained and more likely to have access to external capital, have significant effects on improving productivity and added value (Gatti \& Love, 2008; Butler \& Cornaggia, 2011; Levine $\&$ Warusawitharana, 2014). However, there are some studies showing that financial constraints do not have any clear effect on the productivity of industries (Moreno Badia \& Slootmaekers, 2009) or they can only have a negative effect on labor productivity in firms having low labor productivity (Nunes et al., 2007). Empirical studies show that the biggest difficulty in evaluating the impact of financial constraints on the development of firms is the selection of proxy variables, which reflect financial constraints when accessing external capital. Since the financial constraints are unobservable, previous empirical studies usually select proxy variables for financial constraints, such as: (i) some single indicators related to financial activities (debt growth, financial leverage and sensitivity of cash flows to make investment); (ii) composite index based on a set of single index combined by constant/fixed coefficients over time. However, the choice of variables representing financial constraints by single index or combined index in the studies remains limited because of two reasons. Firstly, there is no single financial indicator which fully reflects the level of financial constraints of firms. Secondly, the status and level of financial 
constraints of firms may change over time, so fixing the coefficients to build a financial constraint indicator over time can cause deviation in measurement.

Most empirical researches use variables such as labor size and revenue growth to be the development of firms, however, these variables do not fully reflect the development of firms. Some recent studies have used labor productivity and TFP as proxy for indicating the development of firms. These measurements reflect the development of the firms more accurately. TFP reflects not only changes in technological progress, the way of production inputs combination along with market and institutional structure but also errors in measurement and unobserved effects. That the season why we use the productivity growth and TFP as the proxy for the development of firms in this study. To avoid simultaneous bias in estimating the production function, the firm-level TFP in the sample is estimated by using the semi-parametric method of Levinsohn and Petrin (2003).

To evaluate the effects of financial constraints on productivity growth, this study uses an unbalanced panel data of 97,860 firms extracted from enterprise survey data of General Statistics Office Of Vietnam (GSO) in the 2012-2017 period. Firms in the sample are divided into 7 economic industries that belong to the 2-digit VSIC code (Vietnam Standard Industrial Classification 2017, VSIC2017).

The remainder of this paper is organized as follows: Section 2 mentions literature overview. The research methodology is presented in the Section 3. In this section, the models are provided to measure financial constraint index, TFP and quantify the effects of financial constraints on the development of firms by dynamic model with panel data. Section 4 describes data and discusses empirical estimation results. Section 5 gives the conclusions for the study.

\section{Literature Review}

Financial barriers can significantly affect the efficiency of production and business activities of enterprises through many channels: $(i)$ limitation in the ability to expand production, technological innovation and market expansion (ii) restriction in access to land and (iii) restriction in access to information (Canh et al., 2008; Becchetti \& Trovato, 2002). Therefore, firms which are less dependent on external financing or more likely to overcome obstacles to financial access will grow better (Ayyagari et al., 2010; Girma \& Vencappa, 2015). When the internal capital and the ability to access external capital of firms is limited, it will be difficult for firms to invest in physical capital and access to labor. Thus, these difficulties negatively affect the business growth (Carpenter \& Petersen, 2002; Rahaman, 2010; Guariglia et al., 2011; Chen and Guariglia, 2013). The access to finance affects many other aspects of firm performance. Many studies suggest that financial accessibility is an important factor affecting the productivity of firms and thereby deciding on the development of firms. Studies can be divided into two groups. The first group indirectly estimates the effect of financial constraints on firm productivity through 2-step regression. As a first step, the studies measure firm productivity and in the next step, the OLS or GMM method is employed to regress the effect of financial constraints on firm's productivity (Musso \& Schiavo, 2008; Gatti \& Love, 2008; Levine \& Warusawitharana, 2014; Moreno-Badia \& Slootmaekers, 2009; Nunes et al., 2007; Guan \& Lansink, 2006; Chen \& Guariglia, 2013, Li et al., 2018; Jin et al., 2019). The second group estimate production function directly by adding financial constraints variables to production function (Nickell \& Nicolitsas, 1999; Nucci et al., 2005; Chen \& Guariglia, 2013; Pál \& Ferrando, 2010; Ferrando \& Ruggieri, 2015, 2018). However, the results from the studies are heterogeneous in terms of both economic significance and the direction of the effects of financial constraints on productivity growth. The reason for this difference is that studies have used different variables to represent the level of financial constraints at the firm level such as: debt ratio (Nickell \& Nicolitsas, 1999); debt growth (Levine \& Warusawitharana, 2014); financial leverage (Nunes et al., 2007); sensitivity of cash flows for making investment (Fazzari et al., 1988; Chen and Guariglia, 2013) or using the Kaplan and Zingales (KZ) index of financial constraints (Kaplan and Zingales, 1997; Lamont et al., 2001); the CCFS (cash flow sensitivity of cash) index (Almeida et al., 2004); the Whited and Wu (WW) index of constraints (Whited \& Wu, 2006); the size-age (SA) index (Hadlock \& Pierce, 2010). Moreover, productivity and productivity measurement methods used in studies are also different, some used labor productivity, residual of Solow model, others used productivity estimated by Olley-Pakes (1996) or Levinsohn and Petrin (2003), Malmquist productivity index.

Through literature review, there are two limitations in the emperical studies about the effect of financial constraints on productivity growth at the firm level: (i) indirect variables which represent the level of financial constraints may not fully reflect financial constraints level of firms and (ii) some studies faced endogenous phenomena in TFP estimation. In order to overcome these obstacles of previous researches, this study will build a synthetic indicator of financial constraints based on the semi-parametric method of Pal and Ferrando (2010), Ferrando and Ruggieri $(2015,2018)$ and TFP estimated by the method of Levinsohn and Petrin (2003).

\section{Methodology to measure the effect of financial constraints on productivity growth}

This study is based on the approach of Ferrando \& Ruggieri $(2015,2018)$ to formulate financial constraint variable as an index using semi-parametric method at firm level. First of all, firms will be divided into 3 groups of financial constraints (absolutely constrained, relatively constrained and unconstrained firms) based on a set of relationships among variables including: Total Investment, Financing Gap, Changes of Total Debt, Average interest rate firms pay on debts compared to the average interest rate in the credit market. Then, probit/logit regression is used to predict probabilities of which group of financial constraint the firm is in and compute a synthetic index of financial constraints. In order to quantify the impact of financial constraints on the change in total factor productivity of Vietnamese firms, this study uses dynamic regression method with panel data 
(DPD) developed by Arellano \& Bond (1991), Arellano \& Bover (1995), Blundell \& Bond (1998) and Roodman (2009). TFP is measured through estimating production function by the semi-parametric regression method of Levinsohn-Petrin at the firm level (2003).

\subsection{Measurement of financial constraint index (FCI)}

Financial constraints in accessing external financial sources can be interpreted as the cost that firms have to spend when accessing external capital. The fewer financial constraints firms have, the lower cost of their ability to access external capital in financial and monetary market is and vice versa. However, the financial constraints faced by firms are in fact an unobservable variable and there are no specific items on the firm's balance sheet that can reveal whether a firm is financially constrained or not. Moreover, the level of financial constraints among firms is different because the financial constraints that firms faced depend on many different factors involved in the firm characteristics such as firm-size, number of years of operation (age of firm), the level of leverage, cash and other assets (Moreno Badia \& Slootmaekers, 2009). Large firms often have mortgage assets, stable profit growth, and diversify their operations at a fairly high level, so they can easily access capital from the financial and monetary market. Meanwhile, new firms or young firms in the market will face many problems such as lack of market information, low reputation, low credit rank and there is no or not enough mortgage asset to meet the loan requirements in the market.

The financial constraint index in this study are based on "a-priori classification" approach, applying a classification scheme based on information derived from the balance sheet and statement income report. A set of financial indicators are designed to classify the financial constraints that firms are facing (Pál \& Ferrando, 2010; Ferrando \& Ruggieri, 2015 and 2018). The different scenarios about the relationship between variables in the set of indicators are determined if a firm is facing absolutely constrained, relatively constrained or unconstrained. The classification of financial constraints groups is reported in Table 1 .

\section{Table 1}

The classification of financial constraints groups

\begin{tabular}{ccccc}
\hline $\begin{array}{c}\text { Group of financial } \\
\text { constraints }\end{array}$ & $\begin{array}{c}\text { Investment in fixed } \\
\text { assets (FI) }\end{array}$ & Financing gap (FG) & $\begin{array}{c}\text { Changes of total } \\
\text { debt (dch) }\end{array}$ & $\begin{array}{c}\text { Average interest pay- } \\
\text { ments rate (RIP) }\end{array}$ \\
\hline $\begin{array}{c}\text { Unconstrained firm } \\
1\end{array}$ & $\geq 0$ & $<0$ & $\geq 0$ & - \\
2 & $\geq 0$ & $\geq 0$ & $>0$ & - \\
\hline Relatively constrained firm & $\geq 0$ & & $<0$ & $\geq$ IR \\
\hline 3 & $\geq 0$ & $<0$ & $>0$ & - \\
4 & $<0$ & $\geq 0$ & $>0$ & - \\
5 & & - & $\leq 0$ & - \\
\hline Absolutely constrained firm & $\geq 0$ & $\geq 0$ & $\leq 0$ & \\
\hline 7 & $<0$ & - & & \\
\hline Note: IR is average lending rate of commercial banks & & & \\
\hline
\end{tabular}

Source: Pal và Ferrando (2010), Ferrando and Ruggieri (2015, 2018)

According to the classification in Table 1, if a firm in a specific year falls in status 1-2, it will be classified into the group unconstrained firm. If falling into the status of 3-5, the firm is classified into relatively constrained firm and if falling into the status of 6-7, it is classified into to absolutely constrained firm. When a firm falls into absolutely constrained group, it cannot access external capital. For firms in the relatively constrained group, they have access to external capital but higher access costs. For unconstrained firms, it is possible for firms to have access to new credits (using financial leverage) with lower financing costs. After determining the classification of financial constraints groups in Table 1, ordered probit/logit regression model will be carried out to calculate the conditional probability that firms will fall into one of three types of constraints. The specification of ordered probit/logit model is written in the general form as follows:

$$
F C I_{i t}=\alpha X_{i t}+\varepsilon_{i}
$$

where: $F C I_{i t}$ is an unobserved variable measuring financial constraints of the ith firm in year $t$ and $F C I_{i t} \in\{0,1,2\}$ equivalent to the 3 constraint groups that firms face (unconstrained, relatively constrained and absolutely constrained firm). $X_{i t}$ is a set of observed regressors that affect the level of financial constraints of firms including variables such as financial leverage $(F L)$, financial costs (debur), and the amount of cash in firms (Casholding) and firm-specific variables such as firm size (micro, small, medium and large-firms) and some of interaction terms between cash holding, financial costs and size, time dummies to control business cycles (Fernando \& Ruggieri, 2015 and 2018). However, differ from the research of Fernando \& Ruggieri (2015 and 2018), in this study, some other control variables are added such as regional variables, industrial/sectoral variables and remove the average variables $\bar{X}_{l}$ over time in the regression model of Mundlak, 1978. Based on the regression results of equation (1), the synthetic financial constraint index $(F C I f)$ is calculated base on the predicted probability for the outcomes that occur from ordered probit/logit regression. This index will be used to measure the degree of financial constraints at the firm level. The FCIf index is calculated as the weighted probability average of the index variable reflecting the degree of a 
firm's financial constraints of firms as Eq. (2).

$$
\boldsymbol{F C I f}_{\boldsymbol{i t}}=\sum_{\boldsymbol{j} \in\{\mathbf{0}, \mathbf{1}, \mathbf{2}\}} \boldsymbol{j} \widehat{\boldsymbol{P}} \boldsymbol{r}\left(\boldsymbol{F C} \boldsymbol{I}_{\boldsymbol{i t}}=\boldsymbol{j}\right), \quad i=1 \ldots N \quad t=1 \ldots T
$$

where $\operatorname{Pr}\left(F C I_{i t}=j\right)$ are predicted probabilities for each firm changed over time $t$ and belong to one of three groups $j$ of financial constraints. The advantage of the FCIf index is that it can be aggregated to assess the extent of financial conditions at the industry level over time.

\subsection{Measurement of Total Factor Productivity (TFP)}

The impact of financial constraints on the development of firms is assessed through TFP growth. When TFP is estimated through the production function, there will be a problem of correlation between unobserved productivity shocks and the use of input levels of firm. This means that firms will respond to positive productivity shocks by expanding output to maximize profit and thus firms need to use more inputs. In contrast, firms will reduce production and less use inputs with negative productivity shocks. It is true, the coefficients estimated from production function by OLS will be biased and lead to biased estimates of TFP. To address this problem, Olley and Pakes (1996) developed an estimation method that uses the investment variable as a proxy for these unobservable shocks. In fact, not all firms have investment activities (non-zero investment value) and firm-level data also shows that investment often changes slowly compared to productivity shocks. This means that productivity shocks are not fully reflected in the firm's behavior. To overcome the limitations of the approach of Olley and Pakes (1996), Levinsohn and Petrin (2003) have proposed an approach to estimate production function using intermediate input variables as representative variables to control unobserved productivity shocks. This approach also allows solving the simultaneous bias problem in estimating the production function. The TFP at firm level in this study is estimated by the semiparametric method of Levinsohn -Petrin (2003) with the production function having the general form represented as Eq. (3).

$$
y_{i t}=\beta_{0}+\beta_{l} l_{i t}+\beta_{k} k_{i t}+\beta_{m} m_{i t}+\omega_{i t}+\eta_{i t} \quad i=1 \ldots N \quad t=1 \ldots T
$$

where: $i$ is firm $i$ in year $t ; y_{i t}$ is the natural logarithm of real VA; $l_{i t}$ and $m_{i t}$ are the natural logarithms of labor and real intermediate inputs respectively; $k_{i t}$ is the natural logarithm of real physical capital; the error term $\varepsilon_{i t} \operatorname{consists}$ of $\omega_{i t}$ and $\eta_{i t}$, where the first part is the state variable affecting the decision rules of the firm on inputs choices. In other words, this component reflects unobserved productivity shocks and it can impact the choices of inputs (the simultaneous bias in production function estimation). The second part is random productivity shocks that is uncorrelated with input choices. The demand function of intermediate inputs $m_{i t}$ is assumed to depend on the variables $k_{i t}$ and $\omega_{i t}$, which can be described as follows:

$$
m_{i t}=m_{i t}\left(k_{i t}, \omega_{i t}\right)
$$

If assuming demand function of intermediate inputs is a monotonically increasing function in $\omega_{i t}$, then the inverse function of intermediate input function can be rewritten as follows:

$$
\omega_{i t}=\omega_{i t}\left(k_{i t}, m_{i t}\right)
$$

Thus, unobserved productivity shocks described in the above equation are a function of two observed input variables $k_{i t}, m_{i t}$. Under the assumption of contemporaneous exogeneity assumption of $\eta_{i t}$, we can rewrite the final regression equation as follows:

$$
E\left(y_{i t} \mid k_{i t}, m_{i t}\right)=\beta_{l} E\left(l_{i t} \mid k_{i t}, m_{i t}\right)+\Phi\left(k_{i t}, m_{i t}\right) \quad i=1 \ldots N \quad t=1 \ldots T
$$

where:

$$
\Phi\left(k_{i t}, m_{i t}\right)=\beta_{0}+\beta_{k} k_{i t}+\omega_{i t}\left(k_{i t}, m_{i t}\right) \quad i=1 \ldots N \quad t=1 \ldots T
$$

The regression results of the production function are based on the Levinsohn -Petrin (2003) approach, total factor productivity (TFP) will be calculated and used in regression in the next section to evaluate the effect of financial constraints on firms' TFP growth.

\subsection{Financial constraints and Total Factor Productivity (TFP)}

In this study, we use total factor productivity (TFP) growth as a proxy for firm development because TFP is a more proper composite index than other indicators. Most of economic variables including dependent and independent variables in econometric models can be endogenized when their present values are affected by their lag values or there is a causality relationship between regressors and explained variables along the time. Therefore, in this study we will use the dynamic panel data model (DPD) developed by Arellano \& Bond (1991), Arellano \& Bover (1995), Blundell \& Bond (1998) and Roodman (2009). This model allows us to solve the heterogeneity and endogeneity of the variables. In addition, the DPD model is also suitable for short time panel data (small T) and large number of observations for each period (large N). The DPD model of this study can 
be described as follows:

$$
\begin{aligned}
& y_{i t}=\sum_{j=0}^{p} \alpha_{j} y_{i, t-j}+x_{i t} \beta_{1}+w_{i t} \beta_{2}+u_{i t} \\
& i=1 \ldots N \quad t=1 \ldots T \\
& u_{i t}=v_{i}+e_{i t} \\
& E\left(v_{i}\right)=E\left(e_{i t}\right)=E\left(v_{i} e_{i t}\right)=0 \text { and } E\left(e_{i t} e_{j s}\right)=0 \forall i, j, t, s, i !=j
\end{aligned}
$$

where: $y_{i t}$ and $y_{i, t-j}$ are vectors of the dependent variable and the lag of the dependent variable of individuals $i$ in time $t$ and $t$-j; $x_{i t}$ is the vector of independent variable $i$ at time $t ; w_{i t}$ is a vector of predetermined or endogenous covariates consisting of the lags of independent variables and time dummies; $v_{i}$ is unobserved individual-level effects and $e_{i t}$ is a random error.

To solve endogeneity problem in DPD model, Arellano and Bond (1991) developed difference GMM regression method, which converte the regression variables to the first-differential form to eliminate individual effects, $v_{i}$, and also help eliminate hidden sources of bias estimation due to omitting variables in regression. However, the difference of predetermined variables is not strictly exogenous, which makes them endogenous variables due to the $w_{i t}$ in some $D . w_{i t}=w_{i t}-w_{i, t-1}$ is correlated with the lag of random error $e_{i, t-1}$ in $D . e_{i t}$. To overcome this phenomenon, Arellano and Bond (1991) use GMM regression with the instrument variable as lags of the endogenous variables in the form of difference. However, Blundell \& Bond (1998) suggest that if the dependent variable has a high correlation between the present value and the previous value in short periods, the method of Arellano and Bond (1991) is ineffective because of weak instrument variables. Arellano \& Bover (1995) and Blundell \& Bond (1998) extend the Arellano and Bond (1991) model with simultaneous consideration of two equations/models (Equations in differences and Equations in level) which is called System GMM. In particular, the instrument variables used are lags of endogenous variables in the form of difference and levels. These changes allow us to work with a small number of instrument variables in the panel data. Based on the system GMM regression method, the empirical model specified in this study will include lags of a synthetic index variable which reflects financial constraints and lags of TFP. The appearance of lags of TFP into the DPD model is fully consistent with assumptions about productivity dynamics according to the approach of Olley - Pakes (1996) and Levinsohn - Petrin (2003). This is necessary to correct for serial correlation (Fernandes, 2007). Empirical model is specified as follows:

$$
\operatorname{tfp}_{i t}=\alpha_{0}+\alpha_{1} \text { FCIf }_{i t-1}+\delta \text { tfp }_{i t-1}+D^{\prime} \gamma+\varepsilon_{i t}
$$

where: $t f p=\log (T F P) ; D^{\prime}=\left[D_{j}^{\prime} D_{s}^{\prime} D_{o}^{\prime} D_{t}^{\prime}\right]$ are column vectors of dummy variables representing industry, size, ownership and time dummy, respectively. Time dummy variable is given to control cyclicality and trend of the macro environment. $\varepsilon_{i t}$ is the error term. Eq. (9) is estimated by the GMM method, in which the logarithmic value of TFP is regressed on its lagged value (Arellano \& Bond, 1991; Arellano \& Bover, 1995; Blundell \& Bond, 1998; Roodman, 2006) and the lagged value of the financial constraint index. The instrument variables used include both the lags of total factor productivity and explanatory variables.

\section{Empirical estimation results}

\subsection{Data description}

Data used in the study is drawn from enterprise survey data of General Statistics Office (GSO). Building a synthetic index reflecting financial constraints in accessing external capital of firms requires full relevant information on the financial and monetary situation, similarly to the information extracted from the balance sheet and income statement of firms. In order to have enough data and indicators collected in the enterprise survey, we choose research period from 2012 to 2017 . This is also the period after the global financial crisis. In this period, Vietnam economy has been changing thanks to positive financial and credit policies with aiming at supporting the development of private firms. After removing duplicate observations, observations with missing value, observations with zero and negative values of labor, total asset, fixed asset, revenue, gross output, materials and filtering firms existed in the 2012-2017 period, we obtain an unbalanced panel data set of 97,860 firms covering in 7 industries that belong to the 2-digit VSIC code: (1) manufacturing (2) electricity, gas and water, (3) construction and real estate (4) wholesale and retail trade (5) transportation and storage (6) Accommodation and Food service activities (7) Information, communication, scientific and technical activities. This data set shows that the number of firms in the industry (1) is highest while the number of firms in the industry (2) is the smallest. The large-scale firms account for $19 \%$ of total firms and the remaining percentage is small and medium enterprises. The percentage of private firms is $81.9 \%$, which followed by foreign enterprises (14.4\%) and state-owned enterprises (3.7\%). The industries (4) and (6) have number of private firms accounting for more than $90 \%$ of firms running in the industries. Among six socio-economic regions - (1) Northern Midlands and Mountains Area (2) Red River Delta (3) North Central and Central Coast Area(4) Central Highlands (5) South East (6) Mekong River Delta - the largest number of firms is concentrated in regions (2) and (5), which are two key economic regions of the whole country accounting for $34 \%$ and $20.6 \%$ respectively. The region (4) has the smallest number of enterprises in the sample. 


\subsection{Financial constraint index (FCIf)}

Based on the approach of Pál and Ferrando (2010) and Ferrando and Ruggieri (2015, 2018), financial constraints are identified and divided into 3 groups: unconstrained, relatively constrained and absolutely constrained. The ordered probit/logit with random effects has been performed to calculate synthetic index of financial constraints. Logit regression is also performed as a reference to compare estimated results from the probit regression method. The dependent variable is an ordered variable with 3 outcomes: unconstrained, relatively constrained and absolutely constrained. The independent variables are those that affect the firm's ability on accessing external finance including: financial leverage (FL); debt payment burden (debur); cash holding rate (casholding); firm size measured through total assets at 2010 constant prices (fsize); and some variables show the interaction between the above variables and firm size variable. Dummy variables representing regions, industries, types of firms (micro, small, medium and large) and time are also included in the model.

Table 2

The regression results of Ordered Probit/Logit Model

\begin{tabular}{lcc}
\hline & $\begin{array}{c}\text { Ordered Probit Model (OPM) } \\
\text { Coef. }\end{array}$ & Ordered Logit Model (OLM) \\
Coef.
\end{tabular}

Table 2 shows the regression results of ordered probit/logit regression model. The estimated coefficients of financial leverage variable $(F L)$ in both regression methods are positive and statistically different from zero at $1 \%$ confidence level. This reflects the fact that firms with larger debt ratios will face greater financial constraints or face additional costs for them access to new loans. This result is also supported by positive estimated coefficients of the debt payment burden (debur). The estimated coefficient of cash holding variable (casholding) in both models shows a negative and statistically significant effect on the firm's ability in external capital accessibility. It implies that if a firm has a higher proportion of cash holdings, it will reduce the financial constraints that the firm faces. Because the holding of money of non-financial firms is to maintain internal resources to meet for precautionary motive. The scale variable $(f$ size $)$ has a negative and statistically significant effect on financial constraints. The findings are similar to the result in many previous studies is that the bigger the asset scale of firm, the better its ability to access external capital. However, when the capital market in Vietnam is underdeveloped, imperfect information is becoming a major barrier for firms in accessing external capital, especially for small and medium enterprises (SMEs), new and young firms. The financial structure of small-sized firms is often underestimated by credit institutions due to the asymmetric information. The relatively low levels of accountability of credit, the poor bookkeeping records; the absence of credible collateral; a lack of transparency lead difficulties for firms to access different financial sources in the market. Based on the results of ordered probit and logit regression, the synthetic index of financial constraint is calculated a weighted average of the probability that the firm is expected to be financial constrained or unconstrained. The results of the correlation test show that the index of financial constraint calculated by the probit and logit regression is equivalent with the correlation coefficient of 0.9994 at the statistical significance level of $1 \%$. Thus, the estimated synthetic index of financial constraint is reliable.

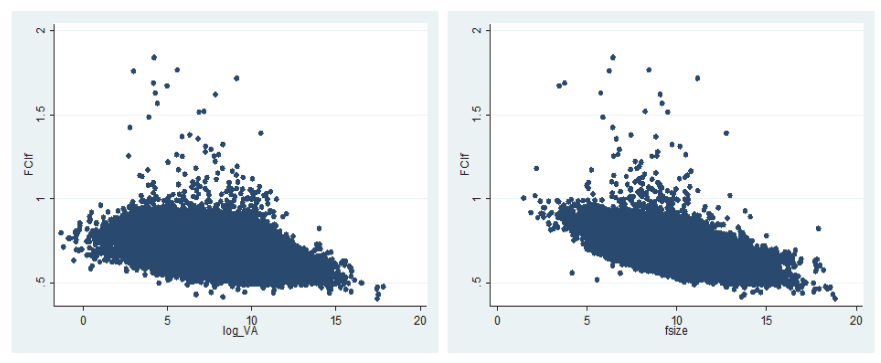


Fig. 1. Relationship between FCIf and VA and Total Assets of firm (Source: Author's own calculations)

Fig. 1 presents the scatter plot of financial constraint index FCIf and Value Added (VA) and firm scale of the total assets, Fig. 1 shows that firms with low FCIf index, the scale of Value Added and assets is higher. There is a clear effect of financial constraints on the firm performance.

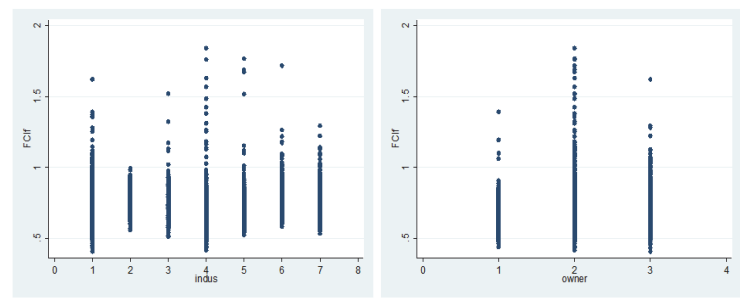

Note: owner: 1 = state-owner enterprise, $2=$ private enterprise, $3=$ foreign capital enterprise

Source: Author's own calculations

Fig. 2. FCIf by Industry and Ownership
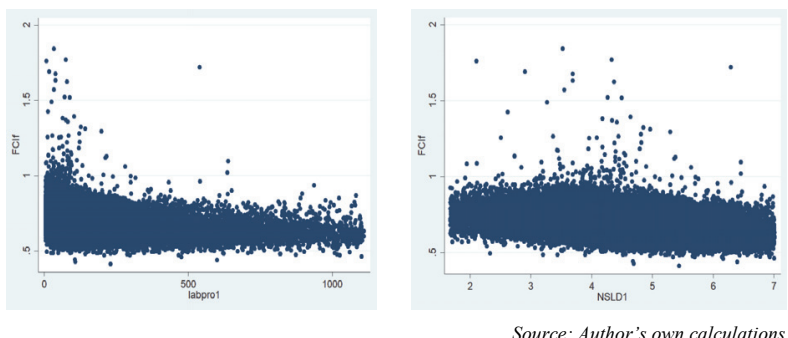

Fig. 3. Relationship between FCIf and labor productivity (labpro) and growth of labor productivity (NSLD)

Looking at the industry and ownership side, Fig. 2 shows that the number of firms facing financial constraints to access external capital in the industry 4 (wholesale and retail trade) and industry 1 (manufacturing) is higher than other industries. Firms in private sector face the biggest financial constraints compared to other types of ownership. Fig. 3 shows a negative relationship between the financial constraint index and labor productivity of firms in the sample. This implies that if firms face greater financial constraints in accessing external capital, labor productivity tends to be lower than firms with low degree of constraint.

\subsection{The effect of financial and monetary constraint index on TFP growth}

The TFP at firms' level is estimated using the semi-parametric method of Levinsohn and Petrin (2003). The production function is estimated with intermediate input variable in order to control unobserved productivity shocks and solve the simultaneity bias. In addition, we also calculate labor productivity for each firm to test the correlation of the financial constraint index with these two productivity indicators.

Table 3

Correlations between FCIf and labor productivity, TFP

\begin{tabular}{|c|c|c|c|}
\hline A. Industries & labpro & NSLD & $\operatorname{lntfp\_ lp}$ \\
\hline Manufacturing & $-0.4519 * * *$ & $-0.5101 * * *$ & $-0.5613 * * *$ \\
\hline Electricity, Gas and Water & $-0.6497 * * *$ & $-0.6475 * * *$ & $-0.8186^{* * *}$ \\
\hline Construction and Real Estate & $-0.3700 * * *$ & $-0.4271 * * *$ & $-0.4488 * * *$ \\
\hline Wholesale and Retail Trade & $-0.3197 * * *$ & $-0.3816^{* * *}$ & $-0.3981 * * *$ \\
\hline Transportation and Storage & $-0.3703 * * *$ & $-0.3840 * * *$ & $-0.4117 * * *$ \\
\hline Accommodation and Food service activities & $-0.3192 * * *$ & $-0.3339 * * *$ & $-0.2674 * * *$ \\
\hline 7. Information, communication, scientific and technical activities & $-0.3112 * * *$ & $-0.3194 * * *$ & $-0.3342 * * *$ \\
\hline B. Full sample (all firms) & $-0.3236 * * *$ & $-0.3899 * * *$ & $-0.5312^{* * *}$ \\
\hline
\end{tabular}

Note: labpro $=$ VA/No. of labor; NSLD $=\log \left(\right.$ labpro). Both variables are winsorized at the $1^{\text {st }}$ and $99^{\text {th }}$ percentiles. $\operatorname{lntfp} l p$ is natural logarithm of TFP

The correlation test results in Table 3 show that both labor productivity and TFP are negatively correlated at the statistical significance level 1\% with the financial constraint index. This implies that the financial constraints faced by firms affect the development of firms, particularly having a negative effect on labor productivity growth and TFP growth.

Table 4

The effects of FCIf on TFP (GMM estimation on panel data)

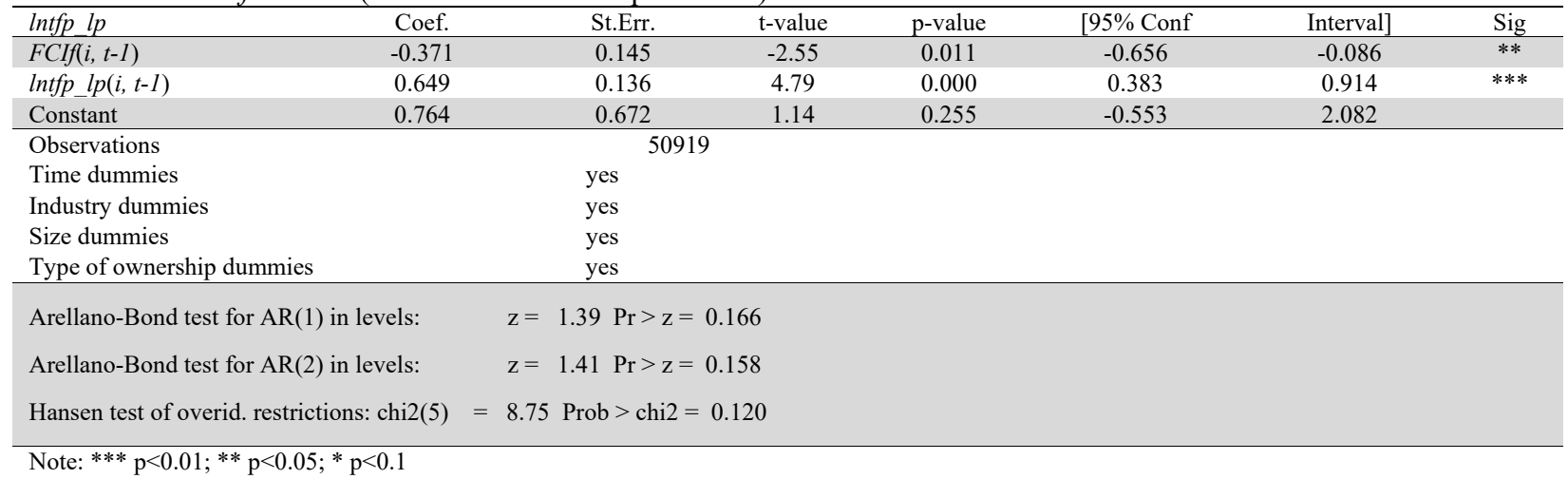

Table 4 presents the regression results of the DPD model according to the GMM method as specified in Eq. (9) to quantify the extent of the effect of financial constraints on TFP growth of firms in sample. In particular, the dependent variable lntfp lp 
is the logarithmic value of TFP estimated by the method of (Levinsohn \& Petrin, 2003) and is regressed with its lagged $\operatorname{lntfp} \_$lp $(i, t-1)$ and lagged value of financial constraint index $F C I f(i, t-1)$. The dummy variables of time, industry, size, and type of ownership are also included in the model to control the cyclical and volatility trend of macro environment. The instrument variables are used in the model including the first and second lags of TFP. Because the FCIf index is built on weightedprobability average of different financial constraint groups as described in equation (2), the value of the FCIf index is from 0 to 2 theoretically. This implies that if a firm has the smaller financial constraint index (approximately zero), the firm has no or less financial constraint in accessing external capital. In contrast, if FCIf index is higher (approximately equal to 2), it is more difficult or impossible for firms to access external capital. Table 4 shows the estimated coefficient of financial constraint index is -0.371 with standard error of 0.145 . This implies that if the FCIf index is increased by 0.1 , the TFP growth of firms will be decreased by $3.71 \%$. This result also correctly reflects the reality of firms in the sample. The higher the degree of financial constraint firms face, the lower ability to access external capital is. This affects the decisions in investment, production expansion and thereby the development of firms, especially having a negative impact on labor productivity and TFP. The results also show that the current policies to support firms to access capital in the financial and monetary market are still limited and the effectiveness of these policies has not been widely promoted in the business community in Vietnam. Private enterprises, especially SMEs, still have difficulty in accessing capital in the market. But it is undeniable that the development of the financial market in recent years has partly reduced the financial constraints for firms. However, in the short term, policy makers need to continue implementing policies to reallocate commercial banks' loans in the direction of reducing the proportion of state-owned enterprises and increase the proportion of private enterprises. In addition, promoting the development of corporate bond market will be the good channel for firms and the whole economy. It will help them to get rid of fully depending on the commercial banking system. In the Table 4, the estimated coefficient of first lag of dependent variable lntfp_lp $\left.p_{t-1}\right)$ is 0.664 and has a statistical significance at level 1\%. It shows that the changes in TFP (increased by $1 \%$ ) in the earlier period has positive effect on TFP of the current period (increased by $0.65 \%$ ).

\section{Conclusions}

In order to evaluate the effect of financial constraints on the development of firms, the study has calculated the financial constraint index (FCIf) according to the a priori classification approach combined with ordered probit/logit regression method. The growth of firms is assessed by the Total Factor Productivity (TFP), which is estimated by semi-parametric method of Levinsohn and Petrin (2003) based on firm-level data set including 97,860 enterprises divided into 7 industries that belong to the 2-digit VSIC2017 code in the period of 2012-2017. The calculated FCIf index shows that: $(i)$ the lower FCIf index is, the larger the firm scale of VA and the assets is; ( $i$ i) wholesale, retail trade and manufacturing firms face more financial constraints than the rest; (iii) private enterprises currently face the greatest financial and monetary constraints compared to other types of ownership; (iv) negative correlation between labor productivity, labor productivity growth, TFP growth and financial constraint index FCIf. The result of regression of dynamic panel data model (DPD) by GMM method shows that if FCIf index is increased by 0.1 , total factor productivity is reduced by $3.71 \%$ and growth TFP of the previous period has a positive effect on TFP growth of the current period. The firms facing higher FCIf index implies that it is more difficult for firms to access external capital in the market, which results in an adverse effect on the growth of total factor productivity of firms and thereby creating barriers limit the ability of business development.

\section{Acknowledgement}

This research is funded by National Economics University, Hanoi, Vietnam.

\section{References}

Almeida, H., Campello, M., \& Weisbach, M.S. (2004). The cash flow sensitivity of cash. The Journal of Finance, 59(4), 1777-1804.

Arellano, M., \& Bond, S. (1991). Some tests of specification for panel data: Monte carlo evidence and an application to employment equations. The Review of Economic Studies, 58(2), 277-297. https://doi.org/10.2307/2297968.

Arellano, M., \& Bover, O. (1995). Another look at the instrumental variable estimation of error-components models. Journal of Econometrics, 68(1), 29-51.

Ayyagari, M., Demirgüç-Kunt, A., \& Maksimovic, V. (2010). Formal versus informal finance: Evidence from China. Review of Financial Studies, Society for Financial Studies, 23(8), 3048-3097.

Becchetti, L., \& Trovato, G. (2002). The determinants of growth for small and medium sized firms: The role of the availability of external finance. Small Business Economics, 19(4), 291-306.

Blundell, R., \& Bond, S. (1998). Initial conditions and moment restrictions in dynamic panel data models. Journal of Econometrics, 87(1), 115-143.

Butler, A. W. \& Cornaggia, J. (2011). Does access to external finance improve productivity? Evidence from a natural experiment. Journal of Financial Economics, 99(1), 184-203. https://doi.org/10.1016/j.jfineco.2010.08.009

Canh, N. T. (2008). Access to finance of Vietnamese small and medium enterprises. Banking Technology Review, $23,28-33$.

Carpenter, R., \& Petersen, B. (2002). Is the growth of small firms constrained by internal finance? The Review of Economics and Statistics, 84(2), 298-309.

Chen, M., \& Guariglia, A. (2013). Internal financial constraints and firm productivity in China: Do liquidity and export behavior make a difference?. Journal of Comparative Economics, 41(4), 1123-1140. 
Fazzari, S. M., Hubbard, R. G., \& Petersen, B. C. (1998). Financing constraints and corporate investment. Brookings Papers on Economic Activity, 1, 141-195.

Fernandes, A. M. (2007). Trade policy, trade volumes and plant-level productivity in Colombian manufacturing industries. Journal of International Economics, 71(1), 52-71. https://doi.org/10.1016/j.jinteco.2006.03.003

Fernando, A., \& Ruggieri, A. (2015). Financial constraints and productivity: evidence from euro area companies. ECB Working Paper Series. https://doi.org/10.1111/j.1467-629X.1980.tb00220.X

Ferrando, A., \& Ruggieri, A. (2018). Financial constraints and productivity: Evidence from euro area companies. International Journal of Finance \& Economics, 23(3), 257-282

Gatti, R., \& Love, I. (2008). Does access to credit improve productivity?. The Economics of Transition, 16(3), $445-465$. Retrieved from https://ideas.repec.org/a/bla/etrans/v16y2008i3p445-465.html

Guan, Z., \& Lansink, A. O. (2006). The source of productivity growth in Dutch agriculture: A Perspective from Finance. The American Journal of Agricultural Economics, 88(3), 644-56.

Guariglia, A., Liu, X., \& Song L. (2011). Internal finance and growth: microeconometric evidence on Chinese firms. Journal of Development Economics, 96, 79-94.

Girma, S., \& Vencappa, D. (2015). Financing sources and firm level productivity growth: evidence from Indian manufacturing. Journal of Productivity Analysis, Springer, 44(3), 283-292.

Hadlock, C. J., \& Pierce J. R. (2010). New evidence on measuring financial constraints: Moving beyond the KZ index. The Review of Financial Studies, 23(5), 1909-1940.

Jin, M., Zhao, S., \& Kumbhakar, S. (2019). Financial constraints and firm productivity: Evidence from Chinese manufacturing. European Journal Of Operational Research, 275(3), 1139-1156.

Kaplan, S. N., \& Zingales, L. (1997). Do investment-cash flow sensitivities provide useful measures of financing constraints?. The Quarterly Journal of Economics, 112(1), 169-215.

Lamont, O., Polk, C., \& J. Saa'-Requejo (2001). Financial constraints and stock returns. Review of Financial Studies, 14, 529-544.

Levine, O., \& Warusawitharana, M. (2019). Finance and productivity growth: Firm-level evidence. Journal of Monetary Economics.

Levinsohn, J., \& Petrin, A. (2003). Estimating production functions using inputs to control for unobservables. Review of Economic Studies, 70(2), 317-341. https://doi.org/10.1111/1467-937X.00246

Li, Y. A., Liao, W., \& Zhao, C. C. (2018). Credit constraints and firm productivity: Microeconomic evidence from China. Research in International Business and Finance, Elsevier, 45(C), 134-149.

Moreno, B. M., \& Slootmaekers, V. (2009). The Missing Link between Financial Constraints and Productivity (No. WP-0972).

Mundlak, Y. (1978). On the pooling of time series and cross section data. Econometrica, 46, 69-58.

Musso, P., \& Schiavo, S. (2008). The impact of financial constraints on firm survival and growth. Journal of Evolutionary Economics, 1892, 135-149

Nickell, S., \& Nicolitsas, D. (1999). How does financial pressure affect firms? European Economic Review, 43, $1435-56$.

Nucci, F., Pozzolo, A. F., \& Schivardi, F. (2005). Is firm's productivity related to its financial structure? Evidence from microeconomic data. Rivista di Politica Economica, 1-2, 177-98.

Nunes, P., Sequeira, T., \& Serrasqueiro, Z. (2007). Firm's leverage and labour productivity: a quantile approach in Portuguese firms. Applied Economics, 39(14), 1783-1788.

Olley, G. S., \& Pakes, A. (1996). The dynamics of productivity in the telecommunications equipment industry. Econometrica, 64(6), 1263-1297. https://doi.org/10.2307/2171831

Pál, R., \& Ferrando, A. (2010). Financing constraints and firms' cash policy in the euro area. European Journal of Finance, 16(2), 153-171. https://doi.org/10.1080/13518470903075748

Rahaman, M. M. (2010). Access to financing and firm growth. Journal of Banking \& Finance, 35, 709-723.

Roodman, D. (2009). How to do xtabond2: An introduction to difference and system GMM in Stata. Stata Journal 9, 86-136.

Whited, T. \& Wu, G. (2006). Financial constraints risk. Revenue Finance Studies, 19(2), 531-59. 


\section{Appendix}

\section{Appendix A}

Definition and construction of FCI and FCIf indicators

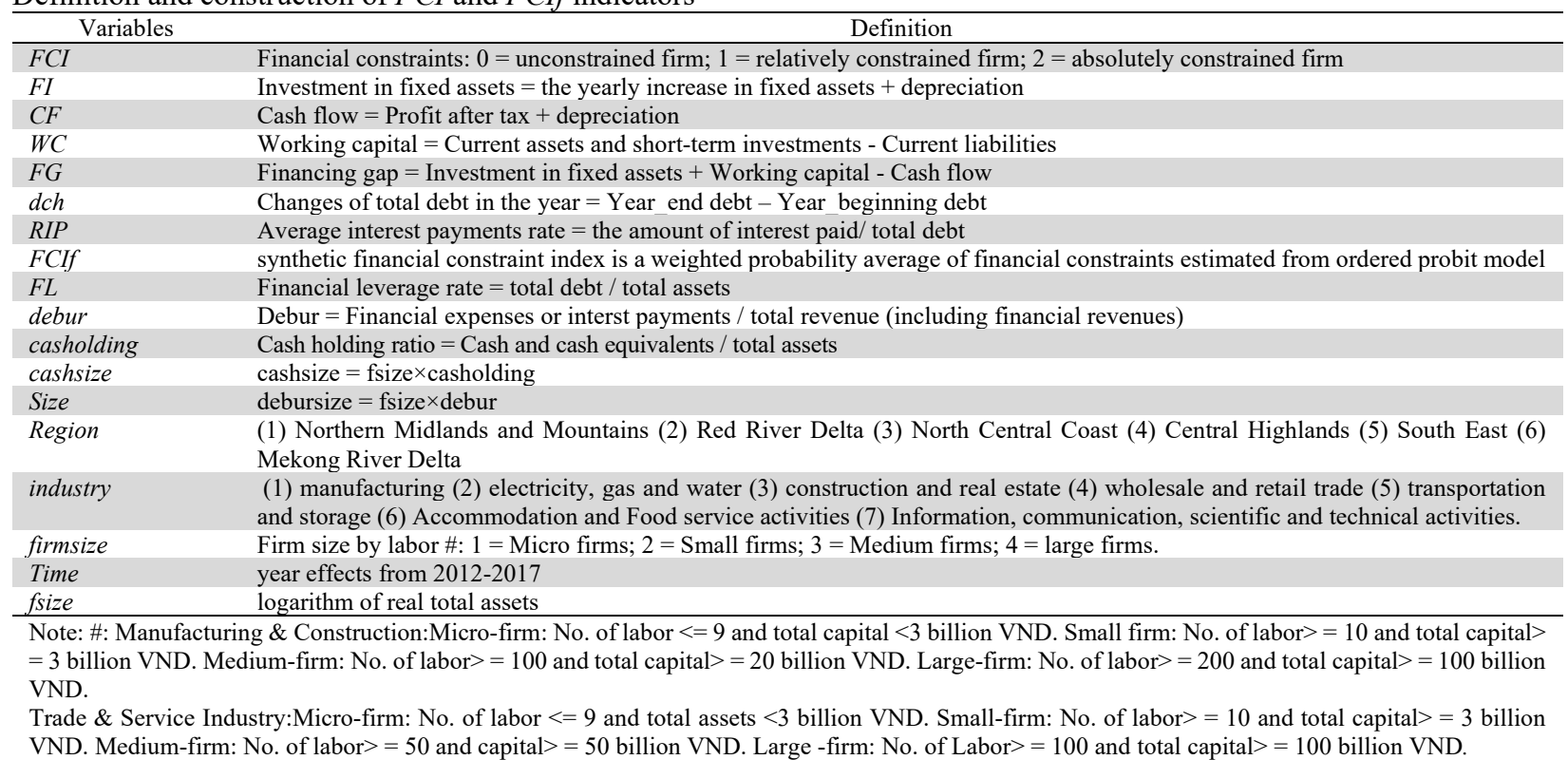

\section{Appendix B}

Define variables used in the production function to measure TFP

\begin{tabular}{|c|c|}
\hline Variable & Definition \\
\hline $\log _{-} V A$ & $\begin{array}{l}\text { Natural logarithm of real value added (VA) at } 2010 \text { constant price; VA }=\text { VAp/def (VAp valued at current price and def: deflator } \\
\text { index of the industry, } 2010=100)\end{array}$ \\
\hline $\log \_m_{-} m$ & $\begin{array}{l}\text { Natural logarithm of real Intermediate inputs at } 2010 \text { constant price: } \mathrm{m}=\mathrm{mp} / \mathrm{def}(\mathrm{mp} \text { : intermediate input valued at current price } \\
\text { and def: deflator index of the industry, } 2010=100)\end{array}$ \\
\hline $\log l$ & Natural logarithm of total labor inputs \\
\hline $\log _{-} k$ & $\begin{array}{l}\text { Natural logarithm of real capital inputs at } 2010 \text { constant price: } \mathrm{k}=\mathrm{kp} / \mathrm{def} \mathrm{k} \text { (kp: capital valued at current and def_k: capital deflator } \\
\text { index) }\end{array}$ \\
\hline $\ln t f p$ & The natural logarithm of TFP that is estimated by the method of Levinsohn \& Petrin (2003). \\
\hline
\end{tabular}

